\title{
Influence of Chemical Degradation and Toothbrushing on Surface of Composites
}

\author{
${ }^{1}$ Carlos Rocha Gomes Torres, ${ }^{2}$ Tânia Mara Da Silva, ${ }^{3}$ Ana Luísa Leme Simões Sales \\ ${ }^{4}$ Cesar Rogerio Pucci, ${ }^{5}$ Alessandra Bühler Borges
}

\begin{abstract}
Objective: The aim of this study was to evaluate the effect of chemical degradation media associated with brushing on surface roughness $(\mathrm{R} a)$ and Knoop microhardness ( $\mathrm{KHN}$ ) analyses of different composites.

Materials and methods: Eighty specimens were prepared for each composite: GrandioSO (Voco), Amaris (Voco), Filtek Supreme (3M ESPE), Filtek LS (3M ESPE). The specimens were divided into four groups according to the immersion in chemical degradation media for 7 days: artificial saliva (control), heptane, $0.02 \mathrm{M}$ citric acid, $70 \%$ ethanol. The surface of specimens was submitted to 10950 brushing cycles (200 gm load) in an automatic toothbrushing machine with abrasive slurry. Surface roughness and microhardness measurements were obtained at baseline, after immersion in chemical degradation media and after brushing. Data were submitted to three-way repeated measures ANOVA and Tukey's test ( $p<0.05)$.
\end{abstract}

Results: The KHN means for composites were: Grandio (153.5 \pm $35.9)^{\mathrm{a}}$, Filtek Supreme $(87.0 \pm 24.9)^{\mathrm{b}}$, Amaris $(64.5 \pm 24.5)^{\mathrm{c}}$, LS $(69.0 \pm 15.3)^{\mathrm{c}}$; for storage media: artificial saliva $(97.3 \pm 46.7)^{\mathrm{a}}$, ethanol $(93.3 \pm 49.9)^{\mathrm{a}}$, citric acid $(95.8 \pm 42.1)^{\mathrm{a}}$, heptane $(87.6 \pm$ $36.7)^{\mathrm{b}}$; and after treatments: after chemical degradation (104.8 \pm 49.7) $)^{\mathrm{a}}$, baseline $(93.8 \pm 42.5)^{\mathrm{b}}$, after brushing $(81.9 \pm 36.5)^{\mathrm{c}}$. The $\mathrm{Ra}$ results for composites were: LS $(0.15 \pm 0.25)^{\mathrm{a}}$, GrandioSO $(0.19 \pm 0.24)^{\mathrm{ab}}$, Filtek Supreme $(0.20 \pm 0.22)^{\mathrm{ab}}$, Amaris $(0.23 \pm$ $0.37)^{\mathrm{b}}$; for storage media: artificial saliva $(0.18 \pm 0.31)^{\mathrm{a}}$, heptane $(0.18 \pm 0.25)^{\mathrm{a}}$, ethanol $(0.20 \pm 0.26)^{\mathrm{a}}$, citric acid $(0.21 \pm 0.28)^{\mathrm{a}}$, and after treatments: brushing $(0.11 \pm 0.14)^{\mathrm{a}}$, after chemical degradation $(0.23 \pm 0.32)^{\mathrm{b}}$, baseline $(0.24 \pm 0.32)^{\mathrm{b}}$.

Conclusion: Brushing after chemical degradation reduced surface roughness values. In general, chemical degradation did not affect composites roughness, but microhardness was significantly reduced. Heptane produced the biggest reduction in composites microhardness.

Clinical relevance: The food-simulating solutions and brushing simulating alter the composites properties, and these alterations are material-dependent.

Keywords: Brushing, Chemical degradation, Composites, Knoop microhardness, Surface roughness.

\footnotetext{
${ }^{1,4,5}$ Assistant P rofessor, ${ }^{2} \mathrm{PhD}$ Student, ${ }^{3}$ Student

${ }^{1-5}$ Department of R estorative Dentistry, Institute of Science and Technology, Universidade Estadual Paulista, São Paulo, Brazil

Corresponding Author: Carlos Rocha Gomes Torres, Assistant Professor, Department of Restorative Dentistry, Avenida Engenheiro Francisco J osé Longo, 777, Jardim São Dimas São J osé Dos Campos, SP, Brazil, CEP: 12245-000, Phone: (12) 39479376, e-mail:carlosrgt@gmail.com
}

How to cite this article: Torres CRG , Da Silva TM, S ales ALLS, Pucci CR, Borges AB. Influence of Chemical Degradation and Toothbrushing on Surface of Composites. World J Dent 2015;6(2):65-70.

\section{Source of support: Nil}

Conflict of interest: None

\section{INTRODUCTION}

Improvements on the composition and mechanical properties of resin-based materials along with increased esthetic demands have resulted in the enlarged use of direct composite restorations in anterior and posterior teeth. ${ }^{1,2}$ These improvements provided more strength and durability to the composite restorations under the conditions of the oral environment. Most of the available composites contain a polymer matrix of dimethacrylate monomers, such as Bis-GMA, UDMA, and TEGDMA (organic phase), inorganic filler particles (dispersed phase) coated with a methyl methacrylate-functional silane coupling agent to bond the filler to the organic matrix, a photoinitiator system to allow photoactivation by light units and other minor additions including polymerization initiators, stabilizers and coloring pigments. ${ }^{3-5}$

However, the critical oral environment conditions ( $\mathrm{pH}$ changes or humidity) may increase the composite biodegradation over time. ${ }^{6}$ Under oral conditions, dental materials may be exposed either intermittently or continuously to chemical agents present in saliva, food and beverages. ${ }^{1}$ Previous studies have shown that some dietary foods and beverages can cause surface degradation of restorative materials. ${ }^{7-14}$ Their constituents can soften the organic phase and promotes disintegration of the dispersed phase, altering the surface hardness. ${ }^{1,15}$

Besides of chemical environment, the toothbrushing is another condition that influences the longevity of composites restorations in vivo. Although toothbrushing plays an important role in oral hygiene, the effects of abrasion constitutes another important issue on dental materials wear processes, which can result in alterations in surface roughness, loss of contour, staining and plaque retention. $^{16}$

There are several types of composites nowadays, such as nanohybrid, nanofill and microhybrid, which 
have the similar polymer matrix composition. However, the inorganic phase (size, type and distribution of filler particles) are different. Therefore, the effects of chemical degradation liquids and toothbrushing on surface roughness and microhardness of these types of composites must be reported.

Thus, the aim of this study was to evaluate the effects of chemical degradation associated with toothbrushing on surface roughness and microhardness of different composites. The null hypothesis tested was that the immersion in chemical degradation media and brushing are not able to modify the surface roughness and microhardness of the tested materials.

\section{MATERIALS AND METHODS}

\section{Specimens Preparation}

Eighty cylindrical specimens of each composite were fabricated (shade A3) using a metallic matrix with $2 \mathrm{~mm}$ in height and $3 \mathrm{~mm}$ in diameter. A mylar strip was placed over the composite and pressed with a glass plate to provide a flat surface, being removed after curing.

The composites were applied in increments of $2 \mathrm{~mm}$ and cured on the top surface using LED photocuring unit (Elipar FreeLight 2, 3M ESPE, St Paul, MN, USA) at $1200 \mathrm{~mW} / \mathrm{cm}^{2}$ power density, activated for 40 seconds. After curing, they were stored in individual containers with deionized water for 24 hours. Then, they were polished using a sequence of 1200, 2400 and 4000 grit aluminum oxide abrasive disks (Extec, Enfield, CT, USA) in a polishing device (DP-10, Panambra, São Paulo, Brazil).
After polishing, all the specimens were immersed in deionized water at $37^{\circ} \mathrm{C}$ for 24 hours.

Four direct restorative materials were tested, as described in Table 1.

\section{Knoop Microhardness Measurements}

The microhardness measurement was performed with a microhardness tester (FM-700, Future-Tech, Tokyo, Japan), Knoop tip, under 25 gm load for 10 seconds. Three indentations were performed $100 \mu \mathrm{m}$ apart from each other, at the surface of the specimens. The means were determined as Knoop hardness number (KHN).

\section{Surface Roughness Analysis}

The mean surface roughness $(\mathrm{Ra})$ was evaluated using a profilometer (MaxSurf XT 20, Mahr, Goettingen, Germany). The diamond stylus moved $2.5 \mathrm{~mm}$ long starting the first measurement $0.2 \mathrm{~mm}$ from the lower area of specimen. Three profile measurements were performed for each specimen at intervals of $0.25 \mathrm{~mm}$ and a final average was used. The mean Ra values were determined with a cut-off value of $0.8 \mathrm{~mm}$, a transverse length of $0.8 \mathrm{~mm}$, and a stylus speed of $0.1 \mathrm{~mm} / \mathrm{s}$.

\section{Chemical Degradation Media Immersion}

The specimens of each composite were randomly divided according to the food-simulated substances tested $(n=20)$. The solutions tested are mediums recommended by FDA (1976) to be used as food-simulating liquids. ${ }^{17}$

Table 1: Compositions of the composites resin tested

\begin{tabular}{|c|c|c|c|c|}
\hline Materials & Batch no. & Type & Composition & Filler content \\
\hline GrandioSO (Voco) & A3-1034125 & Nanohybrid & $\begin{array}{l}\text { Inorganic fillers in a } \\
\text { methacrylate matrix } \\
\text { (Bis-GMA, TEGDMA, } \\
\text { UDMA) }\end{array}$ & $89 \% \mathrm{w} / \mathrm{w}$ \\
\hline Amaris (Voco) & TN-0843320 & Microhybrid & $\begin{array}{l}\text { Inorganic fillers } \\
\text { in a methacrylate } \\
\text { matrix (Bis- } \\
\text { GMA,UDMA,TEGDMA) }\end{array}$ & $80 \% \mathrm{w} / \mathrm{w}$ \\
\hline $\begin{array}{l}\text { Filtek Supreme } \\
\text { (3M ESPE) }\end{array}$ & A3E-1036300094 & Nanofill & $\begin{array}{l}\text { Inorganic fillers in a } \\
\text { methacrylate matrix } \\
\text { (Bis-EMA, UDMA,B is- } \\
\text { GMA, TEGDMA), } 20 \mathrm{~nm} \\
\text { silica filler, } 4 \text { to } 11 \mathrm{~nm} \\
\text { zirconia filler, zirconia/ } \\
\text { silica cluster filler }\end{array}$ & $78.5 \% \mathrm{w} / \mathrm{w}$ \\
\hline $\begin{array}{l}\text { Filtek LS } \\
\text { (3M ESPE) }\end{array}$ & A3-N 130928 & Microhybrid & $\begin{array}{l}\text { Silorane resin } 23 \% \text {, } \\
\text { quartz filler, yttrium } \\
\text { fluoride, stabilizer } \\
0.13 \% \text {, initiator } 0.9 \% \\
\text { (camphorquinone, } \\
\text { iodonium salt, electron } \\
\text { donor), pigments } \\
0.005 \%\end{array}$ & $76 \% \mathrm{w} / \mathrm{w}$ \\
\hline
\end{tabular}


Heptane PA (Synth, Labsynth, Diadema, São Paulo, Brazil) was used to simulate butter, fat meals and vegetable oils. Citric acid 0.02 M (Synth) simulated beverages, vegetables, fruits and candies. Ethanol 70\% (Zulu Hospitalar 70\%-Companhia Nacional de Álcool, Piracicaba, São Paulo, Brazil) simulated alcoholic beverages and mouthrinses. Artificial saliva was used as control and prepared according to Gohring et $\mathrm{al}^{18}$ using $22.1 \mathrm{mmol} / \mathrm{lhydrogen}$ carbonate, $16.1 \mathrm{mmol} /$ lof potassium, $14.5 \mathrm{mmol} / 1$ sodium, $2.6 \mathrm{mmol} / 1$ hydrogen phosphate, $0.8 \mathrm{mmol} / 1$ boric acid, $0.7 \mathrm{mmol} / 1$ calcium, $0.4 \mathrm{mmol} / 1$ thiocyanate and $0.2 \mathrm{mmol} / \mathrm{l}$ magnesium.

The specimens were kept in individual vials with $2 \mathrm{ml}$ of each solution for 7 days at $37^{\circ} \mathrm{C}$. After this period, the specimens were washed thoroughly, and stored in deionized water at $37^{\circ} \mathrm{C}$, for 24 hours. The microhardness and surface roughness were evaluated.

\section{Brushing Protocols}

Subsequently, the experimental units were subjected to brushing abrasion in an automatic toothbrushing (TB) machine (ODEME Biotechnology_-Joaçaba, Santa Catarina, Brazil) which imparted reciprocating motion to 6 soft bristle toothbrush heads (Sanifill Ultraprofessional, Hypermarcas-São Paulo, Brazil). This apparatus provides linear brushing movements across the specimens at a speed of 120 cycles per minute at $37^{\circ} \mathrm{C}$, with a double pass of the brush head over the surface. The top surface of resin composites cylinders were submitted to 10950 brushing stokes under a vertical load of $200 \mathrm{gm}$ with abrasive slurry, simulating 1 year of clinical situation. ${ }^{19}$ The abrasive slurry consisted of fluoridated dentifrice (Colgate Tripla Ação, Colgate-Palmolive, São Paulo, Brazil) and artificial saliva, in a ratio of 1:3, by weight. ${ }^{20}$ Toothbrushes were replaced after the completion of each brushing cycles. After brushing, the specimens were kept in deionized water at $37^{\circ} \mathrm{C}$, for 24 hours. At the end of this protocol, the microhardness and surface roughness was obtained.

\section{STATISTICAL ANALYSIS}

This experiment followed a factorial scheme of the $4 \times$ $3 \times 4$ type. The experimental variables under study were composites (Grandio, Amaris, Filtek LS, Filtek Supreme), time [baseline, after chemical degradation (CD) and after brushing (TB)] and the food-simulating media [artificial saliva (AS), heptane $(\mathrm{H})$, citric acid (CA) and ethanol (E)]. The variable responses were the mean roughness measurement value obtained in profilometer, and the average of three microhardness readings.

Data were submitted to statistical analysis using the computer software Statistica for Windows (Statsoft, Tulsa, OK, USA). The inferential statistics consisted of three-way repeated measures ANOVA (composites, time, and chemical degradation media), in which the variable time was considered as a repeated factor, followed by Tukey's test. The level of significance was the conventional value of $5 \%$.

\section{RESULTS}

\section{Microhardness Evaluation}

The mean KHN values of the composites after chemical degradation media are shown in Graph 1. The application of RM-ANOVA showed significant differences for the factors composites $(p=0.0001)$, time $(p=0.0001)$ and chemical degradation ( $p=0.0001)$.

Grandio SO composite presented the highest KHN values for all times tested. Amaris and Filtek LS exhibited values significantly lower than Filtek Supreme and Grandio SO (Table 2). For the chemical degradation media factor, the immersion in heptane produced the lowest microhardness means, compared to the other tested media (Table 3). Regarding the different times, the microhardness (KHN) values significantly increased after immersion in chemical degradation media and decreased after brushing, compared to baseline means (Table 4).

\section{Surface Roughness Analysis}

The means of roughness surface ( $\mathrm{Ra})$ for the composites are shown in Graph 2. The application of RM-ANOVA showed no significant differences for composite $(\mathrm{p}=0.034)$ and time $(p=0.626)$ factors.

The roughness means obtained for Amaris composite were significantly higher than Filtek LS. Grandio SO and Supreme exhibited intermediate means (Table 2). For the chemical degradation media, no significant differences were obtained for surface roughness (Table 3). The Ra means after brushing were lower than at baseline and after chemical degradation (CD) (Table 4).

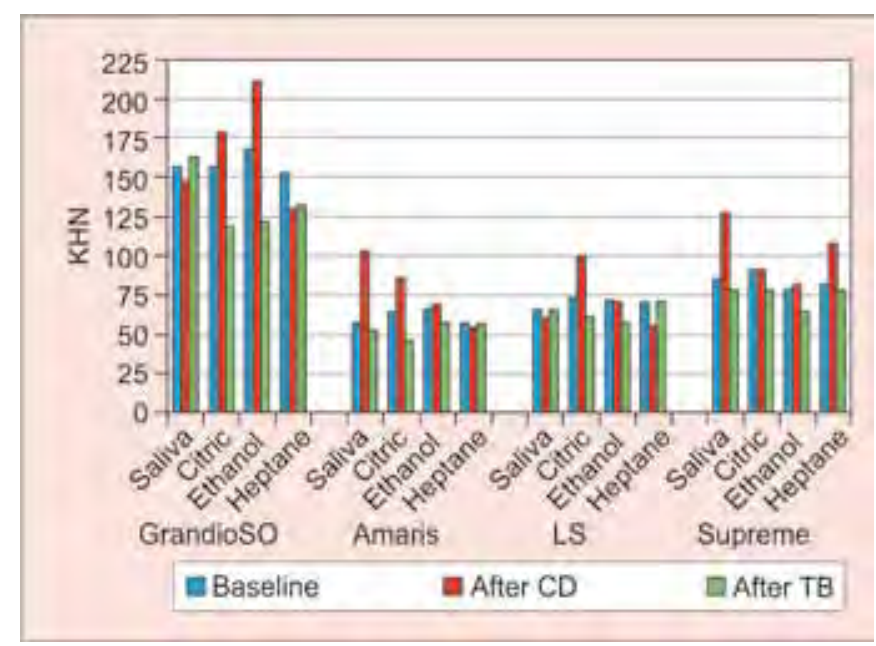

Graph 1: Means of KHN according to the chemical degradation media and times 
Table 2: Microhardness means, surface roughness means and Tukey's test for the composites tested

\begin{tabular}{lccc}
\hline & KHN & & $R a$ \\
\cline { 2 - 2 } Composites & Mean $\pm S D$ & & Mean $\pm S D$ \\
\hline GrandioSO & $153.45 \pm 35.93^{\mathrm{a}}$ & & $0.19 \pm 0.24^{\mathrm{ab}}$ \\
Filtek supreme & $87.03 \pm 24.86^{\mathrm{b}}$ & & $0.20 \pm 0.22^{\mathrm{ab}}$ \\
Filtek LS & $69.03 \pm 15.26^{\mathrm{c}}$ & & $0.15 \pm 0.25^{\mathrm{a}}$ \\
Amaris & $64.47 \pm 24.51^{\mathrm{c}}$ & & $0.23 \pm 0.37^{\mathrm{b}}$ \\
\hline
\end{tabular}

Different letters indicate significant differences among groups $(p<0.05)$

Table 3: Microhardness means, surface roughness means and Tukey's test for chemical degradation solutions

\begin{tabular}{lccc}
\hline & KHN & & Ra \\
\cline { 2 - 2 } Solutions & Mean $\pm S D$ & & Mean $\pm S D$ \\
\hline Artificial saliva & $97.28 \pm 46.74^{\mathrm{a}}$ & & $0.18 \pm 0.31^{\mathrm{a}}$ \\
Citric acid & $95.75 \pm 42.05^{\mathrm{a}}$ & & $0.21 \pm 0.28^{\mathrm{a}}$ \\
Ethanol & $93.35 \pm 49.88^{\mathrm{a}}$ & & $0.20 \pm 0.26^{\mathrm{a}}$ \\
Heptane & $87.61 \pm 36.68^{\mathrm{b}}$ & & $0.18 \pm 0.25^{\mathrm{a}}$ \\
\hline
\end{tabular}

Different letters indicate significant differences among groups $(p<0.05)$

Table 4: Microhardness means, surface roughness means and Tukey's test for the different times

\begin{tabular}{lccc}
\hline & KHN & & $R a$ \\
\cline { 2 - 2 } Times & Mean $\pm S D$ & & Mean $\pm S D$ \\
\hline Baseline & $93.78 \pm 42.51^{\mathrm{b}}$ & & $0.24 \pm 0.32^{\mathrm{b}}$ \\
After CD & $104.81 \pm 49.68^{\mathrm{a}}$ & & $0.23 \pm 0.32^{\mathrm{b}}$ \\
After TB & $81.90 \pm 36.54^{\mathrm{c}}$ & & $0.11 \pm 0.14^{\mathrm{a}}$
\end{tabular}

Different letters indicate significant differences among groups $(p<0.05)$

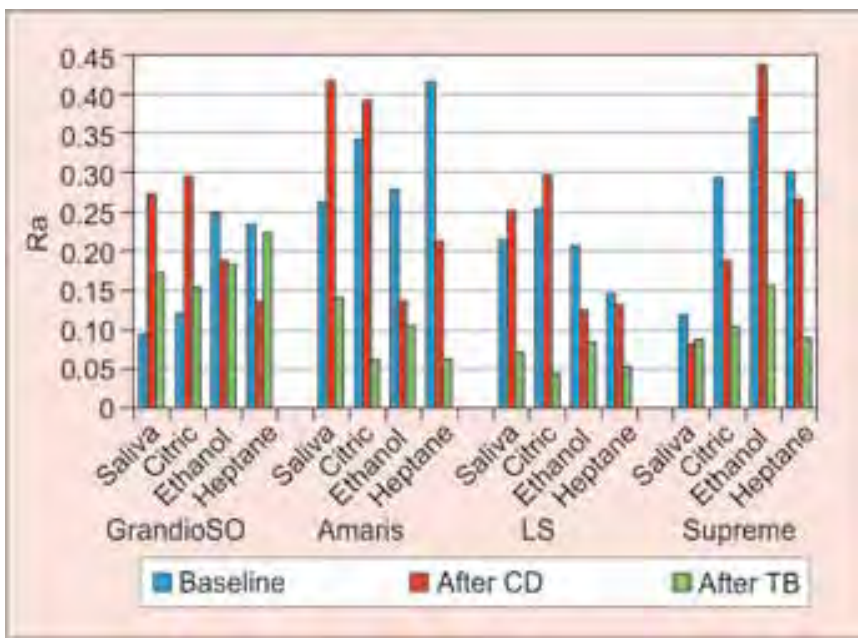

Graph 2: Means of surface roughness (Ra), according to the food-simulating media and times

\section{DISCUSSION}

The chemical environment is one aspect of the oral conditions which has an appreciable influence on the in vivo degradation of composites. ${ }^{21}$ Some chemicals substances from food and drinks can lead to surface degradation of composite restorations, resulting in unesthetic appearance and increased surface roughness, accelerating the wear of dental materials. ${ }^{22,23}$ This degradation is mainly due to the softness of composite matrices with exposure to organic acids and various food and liquid constituents. ${ }^{12,24,25}$ Previously published studies have reported that acidic conditions show a tendency to degrade glass ionomer cements, polyacid modified composite resins, and composite resins. ${ }^{9-11,26,27}$ The present study was performed to investigate the Knoop microhardness and surface roughness of four composites, before and after simulating oral conditions.

Hardness is defined as the resistance to permanent indentation or penetration. ${ }^{1,28}$ It is used to predict the wear resistance of a material and its ability to cause abrasion opposing tooth structure. ${ }^{28}$ The composites exposed in food-simulating media can suffer chemical softening, reducing their physicomechanical properties. Changes in the composite hardness usually occur within the first 7 days after exposure to chemical solutions. ${ }^{21}$ Therefore, this study conducted the initial readings of the hardness in the specimens after post-cure, ${ }^{1}$ and another reading after the exposure period of immersion.

In the present study, specimens stored in heptane showed significantly reduction in microhardness, as also observed previously. ${ }^{14,28}$ Heptane simulates butter, fatty meals and vegetables oil ${ }^{1,14}$ and may damage the resin matrix, ${ }_{1}^{12,28}$ producing cracks in the interface, and consequently, weakening the material. ${ }^{14}$

It is questioned if alcohol-containing beverages may compromise the longevity of composites restorations, ${ }^{29}$ since it presents the potential of damaging polymers, ${ }^{1,12}$ by fully penetrating the resin matrix and promoting the release of unreacted monomers. ${ }^{13}$ The partial dissolving of the resin matrix may result in the degradation of the filler-matrix interface, thereby impairing the flexural strength and hardness. ${ }^{14}$ In this study, the concentration of ethanol solution $(70 \%)$ was used according to previous ${ }^{28}$ but it showed no significant effect in the microhardness of composites. The differences in hardness values compared to previous studies could be related to the surface characteristics of the composites, filler distribution and conversion rate. ${ }^{30}$ Furthermore, the period of 24 hours of storage before immersion in ethanol may lead to complete polymerization of the composites, reducing the presence of unreacted monomers on the surface. ${ }^{1,14}$

The effects of intraoral organic acids, as citric acid, besides producing tooth erosion, can cause surface degradation of composites, ${ }^{9}$ favoring the breaking of bonds in Bis-GMA molecules of composites. ${ }^{11,24}$ Despite of others studies that citric acid reduced the hardness of composites, ${ }^{7,9}$ in this study no differences were observed in the microhardness of the composites when immersed 
in citric acid for 7 days. Nevertheless, the period of storage may have been insufficient to promote differences in the mechanical properties of the specimens' surface. ${ }^{7,14}$

Differences in microhardness means among the composites exposed to the tested solutions were found and are related to their composition and particle content. ${ }^{14,29}$ Grandio SO, Filtek Supreme and Amaris have similar matrix composition (Bis-GMA, UDMA, TEGDMA), however, differ in size and amount of filler particles (Table 1). The higher resistance of Bis-GMA to the degradation effects of immersion media can be explained by the fact that bis-acryl resin composite materials contain bifunctional acrylates, which cross-link to provide increased mechanical strength and resistance to weakening in the presence of solvents. ${ }^{28,31}$

Grandio SO and Filtek Supreme present nanoscale particles, which provide better mechanical resistance compared to hybrid resins, superior polishing than microfilled resins, higher strength and reduced polymerization shrinkage. ${ }^{32}$ Due to their nanoscale, these materials showed the highest microhardness values in this study. By the other hand, Filtek LS is constituted of silorane, with quartz and yttrium fluoride as inorganic filler, which increased hydrophobicity and reduced water sorption. ${ }^{33}$ Differences in microhardness among Filtek LS and others composite could be attributed to the lower filler content $(76 \% \mathrm{w} / \mathrm{w})$, as observed by Yesilyurt et al. ${ }^{14}$ Therefore, the differences in composites compositions could have contributed to the differences in hardness.

After simulated toothbrushing, there was a reduction in microhardness values. This fact may be due to changes on the surface of the resin matrix when immersed in the solutions before brushing. According to a previous study, ${ }^{2}$ the immersion in food-simulating media increased the exposure of filler particles by softening the matrix. Additionally, toothbrushing can change the surface of composites. ${ }^{2,34,35}$ In clinical situation, the consumption of food or beverages occurs before brushing habits, making this association clinically relevant.

Although an increase of the composite surface roughness and degradation after brushing have been previously reported, ${ }^{2}$ significantly lower roughness means were obtained after brushing in this study. Likewise, previous studies showed that most of composites did not present significant changes by the immersion on chemical degradation media in surface roughness over time. ${ }^{2,9,15}$

This study found differences on surface roughness of mycrohybid, nanofill and nanohybrid composites, as results of their differences in their compositions. Filtek LS, myycrohybrid composite, had the lowest surface roughness, probably due to low filler content. Filtek Supreme e Grandio SO had an intermediate smoother texture, whereas Amaris showed the roughest surface.
Nevertheless, despite of these initial differences, the immersion in chemical solutions did not interfere in the final surface roughness.

However, interaction between immersion in foodsimulating media and simulated brushing decreased surface roughness, as observed by Turssi et al. ${ }^{20}$ This may be attributed to the reaction of the solutions with the polymer matrix. Toothbrushing after the immersion on food-simulating media resulted in the removal of part of the organic matrix around the loosen fillers. ${ }^{2}$ Then, the softened matrix have become mixed with the abrasive slurry, decreasing its abrasive potential..$^{20}$ Roughness surfaces of composite favors the accumulation of plaque, gingival inflammation, superficial staining and secondary caries.

It is noteworthy that the effect of brushing on the composites depends on several factors, such as the type of toothpaste, type and shape of the brush bristles, the proportion of deionized-water solution as well as speed and weight applied during simulation process. As these parameters were standardized for all groups, it can be suggested that the surface roughness varies with the size, hardness and percentage of composite particles, as reported previously. ${ }^{20,36}$

The different treatments tested resulted in alteration of composite properties, and these alterations were material-dependent; thus, the null hypothesis tested was rejected. The present study is important for guiding the improvements of the present composite resins against the challenges they will face during clinical service. It is also relevant to state that esthetics represents only one of the reasons for composite resin restorations failure. Improvements in other areas, such as bonding degradation, material deterioration and ability to prevent caries progression/activity should be also considered.

\section{CONCLUSION}

According to the limitations of this study, it can be concluded that:

- The microhardness means of the tested composites were influenced by the material.

- Toothbrushing reduced Ra values of the materials tested, but the solutions used for chemical degradation did not affect the results.

\section{REFERENCES}

1. Yap AU, Tan SH, Wee SS, Lee CW, Lim EL, Zeng KY. Chemical degradation of composite restoratives. J Oral Rehabil 2001 Nov;28(11):1015-1021.

2. Voltarelli FR, Santos-Daroz CB, Alves MC, Cavalcanti AN, Marchi GM. Effect of chemical degradation followed by toothbrushing on the surface roughness of restorative composites. J Appl Oral Sci 2010 Dec;18(6):585-590. 
3. Kalachandra S, Taylor DF, Mc Grath JE, Sankarapandian M, Shobha HK. Structure-property relationships in dental composites based on polydimethacrylates. Polymer Prepr 1997;38:94-95.

4. Peutzfeldt A. Resin composites in dentistry: the monomer systems. Eur J Oral Sci 1997 Apr;105(2):97-116.

5. Sideridou I, Tserki V, Papanastasiou G. Effect of chemical structure on degree of conversion in light-cured dimethacrylatebased dental resins. Biomaterials 2002 Apr;23(8):1819-1829.

6. Soderholm KJ, Zigan M, Ragan M, Fischlschweiger W, Bergman M. Hydrolytic degradation of dental composites. J Dent Res 1984 Oct;63(10):1248-1254.

7. Hengtrakool C, Kukiattrakoon B, Kedjarune-Leggat U. Effect of naturally acidic agents on microhardness and surface micromorphology of restorative materials. Eur J Dent 2011 Jan;5(1):89-100.

8. McKenzie MA, Linden RW, Nicholson JW. The physical properties of conventional and resin-modified glass-ionomer dental cements stored in saliva, proprietary acidic beverages, saline and water. Biomaterials 2003 Oct;24(22):4063-4069.

9. Valinoti AC, Neves BG, da Silva EM, Maia LC. Surface degradation of composite resins by acidic medicines and pH-cycling. J Appl Oral Sci 2008 Jul-Aug;16(4):257-265.

10. De Witte AM, De Maeyer EA, Verbeeck RM. Surface roughening of glass ionomer cements by neutral $\mathrm{NaF}$ solutions. Biomaterials 2003 May;24(11):1995-2000.

11. Turssi CP, Hara AT, Serra MC, Rodrigues AL Jr. Effect of storage media upon the surface micromorphology of resinbased restorative materials. J Oral Rehabil 2002 Sep;29(9): 864-871.

12. McKinney JE, Wu W. Chemical softening and wear of dental composites. J Dent Res 1985 Nov;64(11):1326-1331.

13. Zhang $\mathrm{Y}, \mathrm{Xu}$ J. Effect of immersion in various media on the sorption, solubility, elution of unreacted monomers, and flexural properties of two model dental composite compositions. J Mater Sci Mater Med 2008 Jun;19(6):2477-2483.

14. Yesilyurt C, Yoldas O, Altintas SH, Kusgoz A. Effects of foodsimulating liquids on the mechanical properties of a siloranebased dental composite. Dent Mater J 2009 May;28(3):362-367.

15. Correr GM, Alonso RC, Baratto-Filho F, Correr-Sobrinho L, Sinhoreti MA, Puppin-Rontani RM. In vitro long-term degradation of aesthetic restorative materials in foodsimulating media. Acta Odontol Scand 2012 Mar;70(2):101-108.

16. Kawai K, Iwami Y, Ebisu S. Effect of resin monomer composition on toothbrush wear resistance. J Oral Rehabil 1998 Apr;25(4):264-268.

17. Administration FaD. FDA guidelines for chemistry and technology requirements of indirect additive petitions. Washington: FDA; 1976.

18. Gohring TN, Zehnder M, Sener B, Schmidlin PR. In vitro microleakage of adhesive-sealed dentin with lactic acid and saliva exposure: a radio-isotope analysis. J Dent 2004 Mar;32(3):235-240.

19. Goldstein GR, Lerner T. The effect of toothbrushing on a hybrid composite resin. J Prosthet Dent 1991 Oct;66(4):498-500.

20. Turssi CP, Hara AT, de Magalhaes CS, Serra MC, Rodrigues AL Jr. Influence of storage regime prior to abrasion on surface topography of restorative materials. J Biomed Mater Res B Appl Biomater 2003 May 15;65(2):227-232.

21. Kao EC. Influence of food-simulating solvents on resin composites and glass-ionomer restorative cement. Dent Mater 1989 May;5(3):201-208.

22. Badra VV, Faraoni JJ, Ramos RP, Palma-Dibb RG. Influence of different beverages on the microhardness and surface roughness of resin composites. Oper Dent 2005 MarApr;30(2):213-219.

23. Heintze SD, Forjanic M. Surface roughness of different dental materials before and after simulated toothbrushing in vitro. Oper Dent 2005 Sep-Oct;30(5):617-626.

24. Asmussen E. Softening of BISGMA-based polymers by ethanol and by organic acids of plaque. Scand J Dent Res 1984 Jun;92(3):257-261.

25. Wu W, Toth EE, Moffa JF, Ellison JA. Subsurface damage layer of in vivo worn dental composite restorations. J Dent Res 1984 May;63(5):675-680.

26. Aliping-McKenzie M, Linden RW, Nicholson JW. The effect of Coca-Cola and fruit juices on the surface hardness of glass-ionomers and compomers. J Oral Rehabil 2004 Nov;31(11):1046-1052.

27. Nicholson JW, Millar BJ, Czarnecka B, Limanowska-Shaw H. Storage of polyacid-modified resin composites (compomers) in lactic acid solution. Dent Mater 1999 Nov;15(6):413-416.

28. Akova T, Ozkomur A, Uysal H. Effect of food-simulating liquids on the mechanical properties of provisional restorative materials. Dent Mater 2006 Dec;22(12):1130-1134.

29. Yanikoglu N, Duymus ZY, Yilmaz B. Effects of different solutions on the surface hardness of composite resin materials. Dent Mater J 2009 May;28(3):344-351.

30. Fonseca AS, Gerhardt KM, Pereira GD, Sinhoreti MA, Schneider LF. Do new matrix formulations improve resin composite resistance to degradation processes? Braz Oral Res 2013 Sep-Oct;27(5):410-416.

31. Ireland MF, Dixon DL, Breeding LC, Ramp MH. In vitro mechanical property comparison of four resins used for fabrication of provisional fixed restorations. J Prosthet Dent 1998 Aug;80(2):158-162.

32. Suzuki T, Kyoizumi H, Finger WJ, Kanehira M, Endo T, Utterodt A, et al. Resistance of nanofill and nanohybrid resin composites to toothbrush abrasion with calcium carbonate slurry. Dent Mater J 2009 Nov;28(6):708-716.

33. Weinmann W, Thalacker C, Guggenberger R. Siloranes in dental composites. Dent Mater 2005 Jan;21(1):68-74.

34. Neme AL, Frazier KB, Roeder LB, Debner TL. Effect of prophylactic polishing protocols on the surface roughness of esthetic restorative materials. Oper Dent 2002 JanFeb;27(1):50-58.

35. dos Santos PH, Pavan S, Consani S, Sobrinho LC, Sinhoreti MA, Filho JN. In vitro evaluation of surface roughness of 4 resin composites after the toothbrushing process and methods to recover superficial smoothness. Quintessence Int 2007 May;38(5):e247-253.

36. Berger SB, Palialol AR, Cavalli V, Giannini M. Surface roughness and staining susceptibility of composite resins after finishing and polishing. J Esthet Restor Dent 2011 Feb;23(1):34-43. 